\title{
BMJ Open Youth in a pandemic: a longitudinal examination of youth mental health and substance use concerns during COVID-19
}

\author{
Lisa D Hawke (1) , ${ }^{1,2}$ Peter Szatmari, ${ }^{1,2,3}$ Kristin Cleverley (D) , ${ }^{1,4}$ Darren Courtney, ${ }^{1,2}$ \\ Amy Cheung, ${ }^{2,5}$ Aristotle N Voineskos, ${ }^{1,2}$ Joanna Henderson (iD) ${ }^{1,2}$
}

To cite: Hawke LD, Szatmari P, Cleverley K, et al. Youth in a pandemic: a longitudinal examination of youth mental health and substance use concerns during COVID-19. BMJ Open 2021;11:e049209. doi:10.1136/ bmjopen-2021-049209

- Prepublication history and additional supplemental material for this paper are available online. To view these files, please visit the journal online (http://dx.doi.org/10.1136/ bmjopen-2021-049209).

Received 20 January 2021 Accepted 13 October 2021

Check for updates

(c) Author(s) (or their employer(s)) 2021. Re-use permitted under CC BY-NC. No commercial re-use. See rights and permissions. Published by BMJ.

${ }^{1}$ Centre for Addiction and Mental Health, Toronto, Ontario, Canada ${ }^{2}$ Department of Psychiatry, University of Toronto, Toronto, Ontario, Canada

${ }^{3}$ The Hospital for Sick Children, Toronto, Ontario, Canada ${ }^{4}$ Department of Nursing, University of Toronto, Toronto, Ontario, Canada

${ }^{5}$ Sunnybrook Health Sciences Centre, Toronto, Ontario, Canada

Correspondence to

Dr Joanna Henderson;

joanna.henderson@camh.ca

\section{ABSTRACT}

Objective This study analyses longitudinal data to understand how youth mental health and substance use are evolving over the course of the COVID-19 pandemic, which is critical to adjusting mental health response strategies.

Setting Participants were recruited from among existing participants in studies conducted in an urban academic hospital in Ontario, Canada.

Participants A total of 619 youth aged 14-28 years participated in the study $(62.7 \%$ girls/young women; $61.4 \%$ Caucasian).

Measures Data on mood, substance use and COVID19-related worries were collected over four time points, that is, every 2 months beginning in the early stages of the pandemic in April 2020. Latent class analyses were conducted on the longitudinal data to identify distinct groups of youth who have different trajectory profiles of pandemic impact on their mood, substance use and COVID-19-related worries.

Results For the majority of participants, mood concerns increased early in the pandemic, declined over Canada's summer months and subsequently increased in autumn. Among the youth with the highest level of mood symptoms at the beginning of the pandemic, increases in mental health concerns were sustained. Substance use remained relatively stable over the course of the pandemic. COVID19-related worries, however, followed a trajectory similar to that of mood symptoms. Girls/young women, youth living in urban or suburban areas, in larger households, and with poorer baseline mental and physical health are the most vulnerable to mental health concerns and worries during the pandemic.

Conclusions Youth mental health symptom levels and concerns are evolving over the course of the COVID-19 pandemic, in line with the evolution of the pandemic itself, and longitudinal monitoring is therefore required. It is also essential that we engage directly with youth to cocreate pandemic response strategies and mental health service adaptations to best meet the needs of young people.

\section{BACKGROUND}

The ongoing COVID-19 pandemic is having substantial impacts on the world's population, across many segments of peoples' lives.
Strengths and limitations of this study

- This study prospectively and longitudinally examined mental health and substance use at a bimonthly intervals beginning early in the pandemic.

- Mental health and substance use ratings before the pandemic were reported retrospectively and may have been subject to recall bias.

- The sample was not representative and some diverse groups of youth may not have been reached.

The World Health Organization declared COVID-19 a pandemic on 11 March $2020 .{ }^{1}$ In the months since then, jurisdictions have implemented diverse public health guidelines and directives, including closing business and limiting social contact, with gradual reopenings, all substantially disrupting public life. $^{2}$

At the onset of the pandemic, concerns were rapidly raised about the impacts of these public health steps on the mental health of the population as a whole and on specific vulnerable subgroups. ${ }^{3-7}$ Given research findings from previous quarantines, ${ }^{8}$ the monitoring of mental health and well-being became a priority. Mental health impacts have indeed been observed in the rapidly emerging pandemic research. ${ }^{9-11}$ Metaanalytical data show that rates of depression and anxiety have been higher during the COVID-19 pandemic than in non-pandemic times and are particularly associated with younger age. ${ }^{12} 13$

Youth constitute a particularly vulnerable population in terms of mental health and substance use. ${ }^{6}{ }^{14}$ About one in five youth experience mental health and substance use disorders in Canada ${ }^{15}$ during non-pandemic times, reflecting high prevalence rates internationally. ${ }^{16-18}$ Mental health and substance use disorders often first emerge during 
adolescence and young adulthood. ${ }^{19-21}$ This makes youth a particularly vulnerable group during the COVID-19 pandemic. Many typical developmental milestones, ${ }^{22} 23$ such as schooling, workforce engagement, early career development, relationship development, and autonomous living and decision-making have been disrupted or altered by public health guidelines. In addition, youth already experiencing mental health or substance use concerns prepandemic may experience an exacerbation of their needs, in conjunction with service disruption, ${ }^{724}$ although some may not experience greater concerns and may even experience symptom improvements. ${ }^{25}$

Studies conducted at the emergence of the pandemic suggested high levels of youth mental health and well-being issues and a wide range of concerns, particularly among certain vulnerable subgroups. ${ }^{24}$ 26-31 Concerns include symptoms of post-traumatic stress disorder, ${ }^{27}{ }^{32}$ internalising disorders ${ }^{24}$ and stress and distress in general. ${ }^{27-29}$ Health behaviours such as physical activity and sleep behaviours have been negatively affected. ${ }^{29}{ }^{33} 34$ However, many youth have positive coping strategies that help them manage the pandemic. ${ }^{2428} 29$

However, longitudinal data are urgently needed to understand how youth mental health changes and evolves over the course of the pandemic. ${ }^{35} 36$ The objectives of this study are to: (1) examine trajectories of youth mental health and well-being in a longitudinal manner, bimonthly from April to October 2020, and (2) to understand the characteristics of different youth who have experienced different mental health trajectories during this time. This information will enhance our knowledge of the impacts of the pandemic on the mental health of young people; this knowledge will help guide decision making in responding to the COVID-19 pandemic, future pandemics and other public health emergencies.

\section{METHOD}

\section{Participants and recruitment}

The sample consists of 619 youth between the ages of 14 and 28 years, in line with the Statistics Canada definition of 'youth'. ${ }^{37}$ Recruitment for the study leveraged four existing studies led by the Centre for Addiction and Mental Health (CAMH) in Ontario, Canada, including three clinical studies and a non-clinical study cohort. ${ }^{38-40}$ Participants from the clinical studies were recruited from tertiary-level mental health and/or substance use services for youth, while non-clinical cohort participants were initially recruited from schools in 2011-2013 (see Hawke $e t a l^{4}$ for more details). Participants in the original source cohorts had consented to be contacted for future research.

Recruitment for the first wave of data collection began on 8 April 2020, that is, 3 weeks after the declaration of a state of emergency due to the pandemic in the province of Ontario, Canada, ${ }^{41}$ and continued for approximately 3 weeks. Three subsequent data collection waves were launched at 2-month intervals. All participants who completed the first survey wave were eligible to complete subsequent waves. In Ontario, Canada, April 2020 represented the early pandemic period, when the first wave of COVID-19 cases was rising and public health guidelines to control the spread of the virus were new and strict (ie, substantial shutdown of activity, including closure of all non-essential businesses). In June and August 2020, between the first and second wave of COVID-19 cases in Ontario, the number of cases was progressively declining and public health restrictions were substantially loosened; the first provincial state of emergency was declared over. In September, many youth went back to school either in person or virtually or were home schooled; case counts began to rise, and further restrictions began to be put into place. In October 2020, a second wave of COVID-19 was occurring, with the highest case counts to date; ${ }^{42}$ tightened public health restrictions were put into place on a regional basis in Ontario.

\section{Procedure}

Participants received an email containing a link to an online survey, hosted on REDCap electronic data capture software $^{43}$ on a secure CAMH server. Participants provided informed consent, then completed self-report questionnaires. Survey reminder email messages were sent approximately every $2-3$ days. For each wave, participants received a $\$ 15$ gift card as an honorarium.

\section{Patient and public involvement}

This study employed the principles of youth engagement in research. ${ }^{445}$ Youth were involved in developing supplementary questions for the survey and reviewed the progressive results. The overarching project includes substantial youth engagement from design to knowledge translation; youth coresearchers have partnered throughout the project. Leveraging findings from this project and youth-led discussions, they have produced a series of youth-facing tools on coping with COVID-19, available on the CAMH website. The project will also involve a series of youth summits at the end of the funding period to disseminate knowledge to young people and garner their feedback, guiding our team's next steps in this overarching line of work.

\section{Measures}

Demographics characteristics were collected, including age, current gender identity, ethnic background, employment status and other variables. We also used the CoRonavIruS Health Impact Survey (CRISIS), ${ }^{46}$ Youth Self-Report Baseline V.0.1, which was developed by the National Institute of Mental Health in the USA. For the second wave, we updated the CRISIS survey to include V.0.3 items. Three scales from the CRISIS survey were used: mood states, substance use and COVID-19 worries. ${ }^{47}$ The mood states scale includes 10 items regarding mood and anxiety, including sadness, enjoyment, irritability and concentration issues, among others, answered on a 5-point Likert scale. The Substance Use scale includes frequency of use 
of various substances, including alcohol, cannabis, opiates and others. COVID-19 worries includes seven items rated on a five-point Likert scale regarding the degree of worry about being infected, worry about friends or family being infected, worry about their mental and physical health in the context of the pandemic and the degree of hopefulness about the pandemic ending soon. Mean scores were calculated for each scale, for a score range of 1-5 in each domain. In addition to the four longitudinal time points, the first administration of the CRISIS survey (baseline, April 2020) also asks about mood states and substance use retrospectively at 3 months earlier (January 2020, prior to the pandemic), providing five time points to model for these two scales. The COVID-19 worries scale does not have a retrospective, prepandemic time point, and four time points are therefore available. The CRISIS survey is demonstrating preliminary psychometric validity and reliability. ${ }^{47}$

The GAIN-Short Screener (GAIN-SS) was used to screen for internalising, externalising and substance use disorders and crime/ violence issues. ${ }^{48}$ Participants rate the items on a $0-4$ scale, where 4 indicates the presence of the symptom in the past month. Scale norms suggest that three or more endorsements of past-month symptomatology are consistent with a high likelihood of meeting diagnostic criteria or requiring services in that domain. ${ }^{49}$ Research has validated the GAIN-SS among youth. $^{48}$

\section{Analyses}

Frequencies were used to summarise descriptive statistics. Since demographic characteristics by sample of origin were compared in an earlier publication ${ }^{24}$ with few differences across samples, the current analyses present the clinical and non-clinical samples together to understand trajectories among a broader range of youth. Participants recruited from clinical sources had a significantly different age range than those recruited from non-clinical sources, and age was therefore not analysed. Exploratory analysis revealed that for the April 2020 measurement time, mood states and substance use scales correlated at $r=0.27, \mathrm{p}<0.001$, while the mood states and COVID-19 worries scales correlated at $r=0.55, \mathrm{p}<0.001$, and substance use and COVID-19 worries correlated at $r=0.13, \mathrm{p}=0.001$; strength of the correlations suggested different constructs relevant to analyses in separate models.

We then conducted a latent class analysis (LCA) of the CRISIS survey mood states, substance use and COVID-19 worries scales to observe mental health and substance use trajectories. Full information maximum likelihood was used to include all participants in the analyses. After a first wave of data collection from 619 youth in April 2020, $450(72.7 \%)$ participated at time 2 (June 2020), 410 (66.2\%) at time 3 (August 2020) and $411(66.4 \%)$ at time 4 (October 2020). The sample size was considered sufficient for an LCA approach. ${ }^{50}$ After examining interpretability and LCA fit indices (loglikelihood, parametric bootstrapped likelihood ratio test, Akaike Information
Criterion, Bayesian Information Criterion and sample size-adjusted Bayesian Information Criterion), along with class sizes and interpretability, class models were retained for each of the three scales. Demographic and clinical profiles across the classes for each set of LCA models were examined using $\chi^{2}$ analysis with post hoc tests. Demographic variables were dichotomised or trichotomised based on cell sizes; variables with small cell sizes $(<4)$ were not examined by class. The LCAs were conducted using MPlus, and the remaining analyses were conducted using SPSS V.25.

\section{RESULTS}

Average age was 20.6 years $(S D=2.4$, range $14-28)$. Demographic and clinical characteristics of are presented in table 1. While the univariate majority of participants were Caucasian, female, born in Canada, speaking English as a first language, students, employed and living in large cities with family members, with good to excellent physical health, due to diversity in the sample, only 18 participants $(2.9 \%)$ in the sample met this full nine-variable multivariate profile, demonstrating intersectionality.

Fit statistics for one to six latent classes are presented in the online supplemental material. Based on these findings, in combination with interpretability, the number of classes chosen was as follows: CRISIS survey mood states, 4 classes; substance use, three classes; and COVID-19 worries, three classes.

\section{Mood states}

Four classes demonstrate the longitudinal evolution of mood symptoms over the course of the first 7 months since the pandemic was declared, with a retrospective rating of 3 months prior to the time one assessment (figure 1). All classes of participants reported an increase in mood symptoms early in the pandemic. The largest proportion of participants (class 1: $\mathrm{n}=270,43.6 \%$ ) thereafter showed some decline over Canada's summer months, with some increase in October 2020. The second largest class (class 3: $\mathrm{n}=187,30.2 \%$ ) showed a higher overall level of mood symptoms, with a similar increase in mood symptoms early in COVID-19, followed by a decline, without the October 2020 increase. A small class of participants (class 2: $n=82$, $13.2 \%$ ) expressed the lowest burden of mood symptoms, with the most considerable decline in symptoms over the summer months but a subsequent increase. Another small group (class 4: $n=80,12.9 \%$ ) demonstrated the highest level of mood symptoms. For them, mood symptoms increased early in the pandemic and were sustained.

Comparing the latent classes based on demographic variables (table 2), the class with the lowest level of mood symptom (class 2) consisted of significantly more boys/ young men and fewer girls/young women, as well as significantly more participants living in small city or rural areas compared with large cities or suburbs and participants with better baseline physical and mental health. The latent class with the highest level of mood symptoms 
Table 1 Demographic and clinical characteristics of participants

\begin{tabular}{|c|c|c|c|}
\hline \multicolumn{2}{|c|}{$\begin{array}{l}\text { Demographic and clinical characteristics } \\
(\mathrm{n}=619)\end{array}$} & \multirow{2}{*}{$\frac{\mathbf{n}}{59}$} & \multirow{2}{*}{$\begin{array}{c}\% \\
9.6\end{array}$} \\
\hline Age & $<18$ & & \\
\hline & $18-22$ & 449 & 73.2 \\
\hline & $23-28$ & 105 & 17.1 \\
\hline \multirow[t]{3}{*}{ Gender } & Man/boy & 202 & 32.6 \\
\hline & Woman/girl & 388 & 62.7 \\
\hline & $\begin{array}{l}\text { Transgender or gender } \\
\text { diverse }\end{array}$ & 29 & 4.7 \\
\hline \multirow{7}{*}{$\begin{array}{l}\text { Ethnic origin/ } \\
\text { background }\end{array}$} & Caucasian & 378 & 61.4 \\
\hline & $\begin{array}{l}\text { Asian (East and } \\
\text { Southeast) }\end{array}$ & 65 & 10.6 \\
\hline & South Asian & 46 & 7.5 \\
\hline & $\begin{array}{l}\text { Black (African, } \\
\text { Caribbean, North } \\
\text { American) }\end{array}$ & 28 & 4.5 \\
\hline & Multiple & 48 & 7.8 \\
\hline & Indigenous & 7 & 1.1 \\
\hline & Another background & 44 & 7.1 \\
\hline Born in Canada & & 542 & 87.7 \\
\hline First language English & & 562 & 90.9 \\
\hline Student & & 394 & 63.8 \\
\hline \multirow[t]{3}{*}{ Employment status } & Employed & 374 & 60.7 \\
\hline & Unemployed & 199 & 32.3 \\
\hline & Other & 43 & 7.0 \\
\hline \multirow[t]{3}{*}{ Region of residence } & Large city or suburbs & 414 & 66.9 \\
\hline & Small city & 135 & 21.8 \\
\hline & $\begin{array}{l}\text { Town, village, rural } \\
\text { area }\end{array}$ & 70 & 11.3 \\
\hline \multirow{3}{*}{$\begin{array}{l}\text { Number of people } \\
\text { living with }\end{array}$} & $0-1$ & 102 & 17.2 \\
\hline & $2-4$ & 409 & 68.9 \\
\hline & $5+$ & 83 & 14.0 \\
\hline \multirow[t]{2}{*}{ Living situation } & $\begin{array}{l}\text { With parents and } \\
\text { grandparents }\end{array}$ & 461 & 74.5 \\
\hline & Other & 158 & 25.5 \\
\hline \multirow{2}{*}{$\begin{array}{l}\text { Self-rated physical } \\
\text { health }\end{array}$} & Good to excellent & 506 & 82.1 \\
\hline & Fair or poor & 110 & 17.9 \\
\hline \multirow[t]{4}{*}{ GAIN short screener } & Internalising disorder & 320 & 53.0 \\
\hline & Externalising disorder & 166 & 27.5 \\
\hline & $\begin{array}{l}\text { Substance use } \\
\text { disorder }\end{array}$ & 72 & 11.9 \\
\hline & Crime/violence & 5 & 0.8 \\
\hline
\end{tabular}

(class 4) was significantly more likely to be girls/young women, be living in large cities or suburbs, be living with five or more people, and have poorer physical and mental health. Participants living with parents and/or grandparents compared with other living situations were more likely to be in a class with lower symptom levels. Transgender/gender diverse youth also appeared to be most likely to be in the class with the highest mood symptoms (class 4). Those in the higher mood states symptom classes (classes 3 and 4) were more likely to meet screening criteria for internalising or externalising mental health concerns and were more likely to be in the classes with higher levels of concern for substance use and COVID-19 worries compared with those with profiles of lower mood states scores. There was no difference in class membership based on ethnicity, status as Canadian born, native English speakers, students or employed.

\section{Substance use}

Three classes demonstrate the longitudinal evolution of substance use (figure 1). The majority of participants (class 1: $\mathrm{n}=364,58.8 \%$ ) report low levels of substance use and relatively stable trajectories during the pandemic. Over a quarter of participants (class 2: $\mathrm{n}=171,27.6 \%$ ) fall into a class reporting somewhat higher levels of use, but again relatively stable trajectories. A smaller group of participants (class 3: $n=84,13.6 \%$ ), report the highest level of substance use, again with little variation over time.

The class with the lowest level of substance use (class 1) was significantly more likely to have a background other than Caucasian, to be students, to be living with two to four people, to be living with parents and/or grandparents and to have good physical health, while being significantly less likely to meet criteria for mental health concerns (table 3). Participants in the latent class with the highest substance use concerns (class 3) were more likely to be in the oldest age group, identify as Caucasian, not be students, be living alone or with one other person, not be living with parents/grandparents and to meet screening criteria for an internalising, externalising or substance use disorder. Participants with the highest substance use symptom profile were more likely to be in a higher symptom-level class on the mood states scale, but substance use profiles were not associated with COVID-19 worries profiles. There was no difference between classes in terms of gender, Canadian-born or English-speaking status, employment status or region of residence.

\section{COVID-19 worries}

Three classes demonstrate the longitudinal evolution of COVID-19 worries. All three latent classes reported the highest level of worry early in the pandemic, followed by a decline over the summer, then an increase in October 2020 (figure 1). A large group (class 1: $n=217,35.1 \%$ ) reported the lowest level of worry. For over half of participants (class 2: $\mathrm{n}=322,52.0 \%$ ), worries were moderate compared with the other latent classes. A small but important group (class 3: $\mathrm{n}=80,12.9 \%$ ) reported the highest level of worries and the sharpest increase in October 2020.

The latent class with the lowest level of COVID-19 worries (class 1) consisted of significantly more boys/ young men, participants living in small cities, towns, villages or rural areas and fewer mental health concerns (table 4). The latent class with the most COVID-19 worries (class 3) contained a significantly higher proportion of 
Mood States

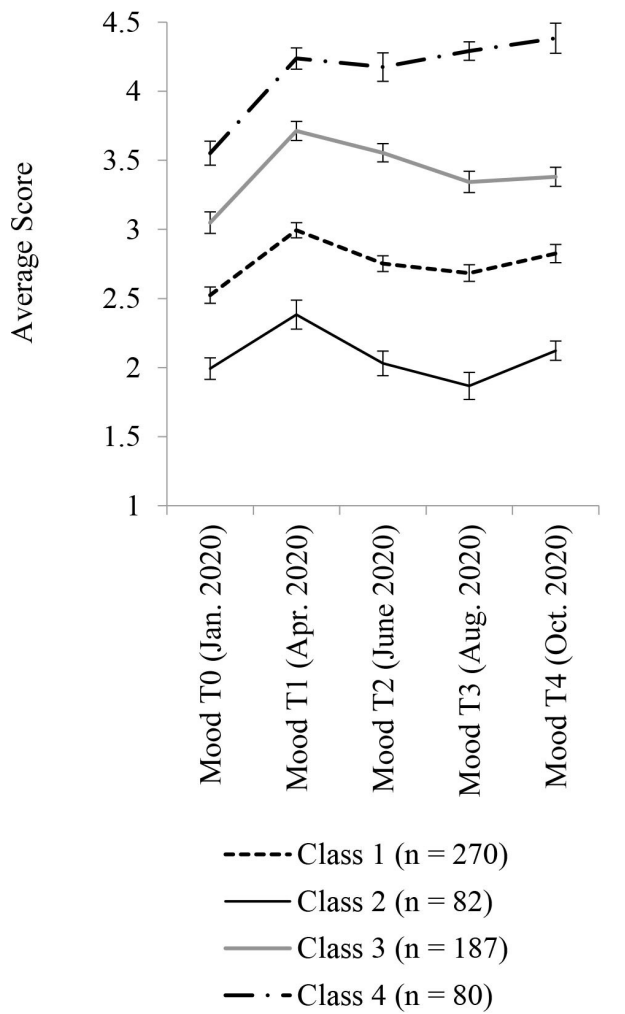

Substance Use
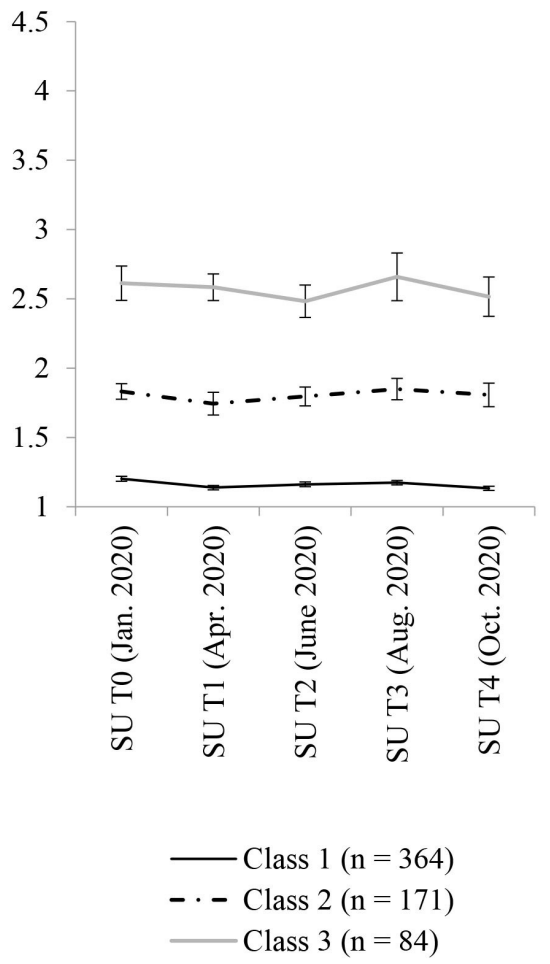

COVID-19 Worries

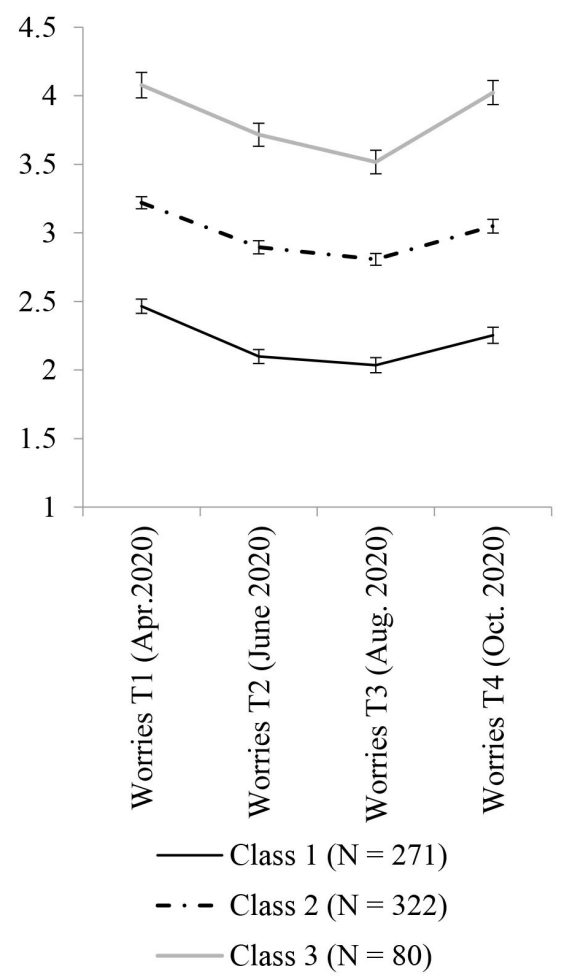

Figure 1 Latent classes of the retained four-class model for the mood states scale, three-class model for the substance use scale and three-class model for the COVID-19 worries scale. Error bars represent the standard error of the mean. Mood, mood states scale; SU, substance use scale; Worries, COVID-19 worries scale.

girls/young women, participants living in large urban or suburban areas and participants screening positive for internalising or externalising disorders at baseline. Transgender/gender diverse youth also appeared to be more likely to be in the highest worries class (class 3). Higher COVID-19 worries were associated with higher symptom classes on the mood states scale, but not substance use. There were no differences in class membership based on age, ethnicity, Canadian-born status, English-language status, student status, employment status, family living situation, number of people living in the home, physical health or the presence of a substance use disorder.

\section{DISCUSSION}

This study examined the longitudinal trajectories of youth mental health, substance use and worries during the COVID-19 pandemic. Results show that course is heterogeneous; youth as a whole were impacted in terms of mental health in the early stages of the pandemic, after which some youth experienced improvements followed by a resurgence of symptoms, while others did not. Particularly affected are girls/young women, possibly transgender/gender diverse youth, ${ }^{31}$ youth living in larger households and in urban or suburban areas and those meeting criteria for mental health or substance use concerns at the beginning of the pandemic. Substance use findings showed that while youth have different levels of substance use, there was little change in use over the course of the pandemic. Levels of pandemic worry vary across youth, with higher levels of worries found among girls/young women, youth living in urban or suburban areas and those meeting criteria for mental health concerns. COVID-19 worries declined as viral transmission declined locally and increased again when transmission increased in the province, particularly for those youth with the greatest level of worry.

A growing number of cross-sectional studies show that the COVID-19 pandemic is having detrimental impacts on youth mental health. ${ }^{24-2631}$ However, the pandemic has been an evolving reality for many months. Individuals and societies have moved beyond the initial shock of the public health emergency, and many are transitioning to a new way of life for the time being. Rates of mental health concerns may vary as COVID-19 infection rates vary in a given area. It is important to note that in the last wave of data collection in the current study, COVID-19 infection rates were sharply rising, which may explain the increase in mood symptoms and worries. Other societal and seasonal factors may have also been affecting young people. For example, many youth went back to school in September after the summer break; while the return to school can have mental health implications for some youth during non-pandemic times,${ }^{52}$ there may be a particular impact during COVID-19, when many youth went back to school 
Table 2 Baseline demographic and clinical characteristics of participants across the four latent classes of the mood states scale

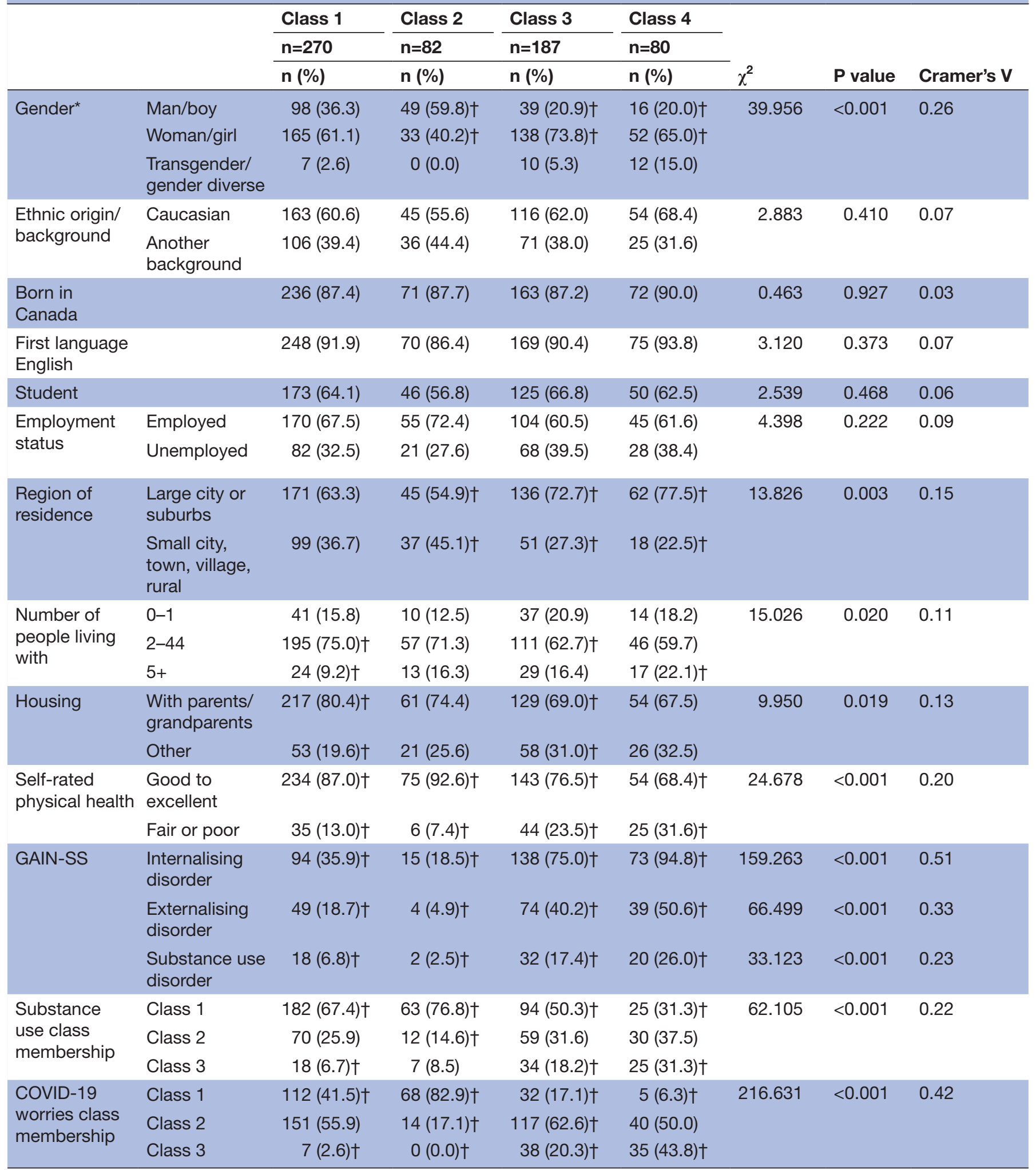

*Significance test conducted on man/boy versus woman/girl due to sample size; when including transgender/gender diverse participants in the significance test on an exploratory basis, these youth were significantly more likely to be in class 4 and significantly less likely to be in classes 1 and 2.

†Post hoc test $\mathrm{p}<0.05$. 
Table 3 Baseline demographic and clinical characteristics of participants across the three latent classes of the substance use scale

\begin{tabular}{|c|c|c|c|c|c|c|c|}
\hline \multirow{3}{*}{\multicolumn{2}{|c|}{$\begin{array}{l}\text { Demographic and clinical } \\
\text { characteristics }\end{array}$}} & \multirow{3}{*}{$\begin{array}{l}\text { Class } 1 \\
\mathrm{n}=364 \\
\mathrm{n}(\%)\end{array}$} & \multirow{3}{*}{$\begin{array}{l}\text { Class } 2 \\
n=171 \\
n(\%) \\
\end{array}$} & \multirow{3}{*}{$\begin{array}{l}\text { Class } 3 \\
\mathrm{n}=84 \\
\mathrm{n}(\%)\end{array}$} & \multirow[b]{3}{*}{$\chi^{2}$} & \multirow[b]{3}{*}{$P$ value } & \multirow[b]{3}{*}{ Cramer's V } \\
\hline & & & & & & & \\
\hline & & & & & & & \\
\hline \multirow[t]{3}{*}{ Gender $^{\star}$} & Man/boy & 115 (31.6) & 58 (33.9) & $29(34.5)$ & 0.855 & 0.652 & 0.04 \\
\hline & Woman/girl & $236(64.8)$ & $100(58.5)$ & $52(61.9)$ & & & \\
\hline & $\begin{array}{l}\text { Transgender/ } \\
\text { gender diverse }\end{array}$ & $13(3.6)$ & $13(7.6)$ & $3(3.6)$ & & & \\
\hline \multirow{2}{*}{$\begin{array}{l}\text { Ethnic origin/ } \\
\text { background }\end{array}$} & Caucasian & $199(55.0) \dagger$ & $117(68.4) \dagger$ & $62(74.7) \dagger$ & 16.055 & $<0.001$ & 0.16 \\
\hline & $\begin{array}{l}\text { Another } \\
\text { background }\end{array}$ & $163(45.0 \%) \dagger$ & $54(31.6 \%) \dagger$ & $21(25.3 \%) \dagger$ & & & \\
\hline \multicolumn{2}{|l|}{ Born in Canada } & $314(86.5)$ & $154(90.1)$ & $74(88.1)$ & 1.378 & 0.502 & 0.05 \\
\hline \multicolumn{2}{|l|}{$\begin{array}{l}\text { First language } \\
\text { English }\end{array}$} & 322 (88.7\%) & 162 (94.7\%) & 78 (92.9\%) & 5.566 & 0.062 & 0.10 \\
\hline \multicolumn{2}{|l|}{ Student } & $253(69.7) \dagger$ & $97(56.7) \dagger$ & $44(52.4) \dagger$ & 13.906 & 0.001 & 0.15 \\
\hline \multirow{2}{*}{$\begin{array}{l}\text { Employment } \\
\text { status }\end{array}$} & Employed & $215(64.2)$ & $105(66.0)$ & $54(68.4)$ & 0.549 & 0.760 & 0.03 \\
\hline & Unemployed & $120(35.8)$ & $54(34.0)$ & 25 (31.6) & & & \\
\hline \multirow[t]{2}{*}{$\begin{array}{l}\text { Region of } \\
\text { residence }\end{array}$} & $\begin{array}{l}\text { Large city or } \\
\text { suburbs }\end{array}$ & $232(63.7)$ & $120(70.2)$ & 62 (73.8) & 4.284 & 0.117 & 0.08 \\
\hline & $\begin{array}{l}\text { Small city, town, } \\
\text { village, rural }\end{array}$ & $132(36.3)$ & $51(29.8)$ & $22(26.2)$ & & & \\
\hline \multirow{3}{*}{$\begin{array}{l}\text { Number of } \\
\text { people living } \\
\text { with }\end{array}$} & $0-1$ & 38 (10.8)† & $38(22.9) \dagger$ & $26(34.2) \dagger$ & 30.808 & $<0.001$ & 0.23 \\
\hline & $2-4$ & 265 (75.3)† & $102(61.4) \dagger$ & $42(55.3) \dagger$ & & & \\
\hline & $5+$ & 49 (13.9) & $26(15.7)$ & $8(10.5)$ & & & \\
\hline \multirow[t]{2}{*}{ Living situation } & $\begin{array}{l}\text { With parents/ } \\
\text { grandparents }\end{array}$ & $300(82.4) \dagger$ & $117(68.4)$ & $44(52.4) \dagger$ & 36.946 & $<0.001$ & 0.24 \\
\hline & Other & $64(17.6) \dagger$ & 54 (31.6) & $40(47.6) \dagger$ & & & \\
\hline \multirow[t]{2}{*}{$\begin{array}{l}\text { Self-rated } \\
\text { physical health }\end{array}$} & $\begin{array}{l}\text { Good to } \\
\text { excellent }\end{array}$ & $310(85.4) \dagger$ & $133(78.7)$ & $63(75.0)$ & 6.913 & 0.032 & 0.11 \\
\hline & Fair or poor & $53(14.6) \dagger$ & $36(21.3)$ & $21(25.0)$ & & & \\
\hline \multirow[t]{3}{*}{ GAIN-SS } & $\begin{array}{l}\text { Internalising } \\
\text { disorder }\end{array}$ & $162(45.5) \dagger$ & 98 (59.0) & $60(73.2) \dagger$ & 23.847 & $<0.001$ & 0.20 \\
\hline & $\begin{array}{l}\text { Externalising } \\
\text { disorder }\end{array}$ & 71 (19.9)† & 57 (34.3)† & $38(46.3) \dagger$ & 28.699 & $<0.001$ & 0.22 \\
\hline & $\begin{array}{l}\text { Substance use } \\
\text { disorder }\end{array}$ & $4(1.1) \dagger$ & $29(17.4) \dagger$ & 39 (47.6)† & 143.650 & $<0.001$ & 0.49 \\
\hline \multirow{4}{*}{$\begin{array}{l}\text { Mood } \\
\text { states class } \\
\text { membership }\end{array}$} & Class 1 & $182(50.0) \dagger$ & 70 (40.9) & $18(21.4) \dagger$ & 62.105 & $<0.001$ & 0.22 \\
\hline & Class 2 & 63 (17.3)† & $12(7.0) \dagger$ & $7(8.3)$ & & & \\
\hline & Class 3 & $94(25.8) \dagger$ & $59(34.5)$ & $34(40.5) \dagger$ & & & \\
\hline & Class 4 & 25 (6.9)† & $30(17.5) \dagger$ & $25(29.8) \dagger$ & & & \\
\hline \multirow{3}{*}{$\begin{array}{l}\text { COVID-19 } \\
\text { worries class } \\
\text { membership }\end{array}$} & Class 1 & $131(36.0)$ & 58 (33.9) & 28 (33.3) & 4.193 & 0.380 & 0.06 \\
\hline & Class 2 & $194(53.3)$ & 87 (50.9) & $41(48.8)$ & & & \\
\hline & Class 3 & 39 (10.7) & $26(15.2)$ & 15 (17.9) & & & \\
\hline
\end{tabular}

*Significance test conducted on man/boy vs woman/girl due to sample size; when including transgender/gender diverse youth in the significance test, there was no significant difference between classes based on gender.

†Post hoc test $\mathrm{p}<0.05$. 
Table 4 Baseline demographic and clinical characteristics of participants across the three latent classes of the COVID-19 worries scale

\begin{tabular}{|c|c|c|c|c|c|c|c|}
\hline \multicolumn{2}{|c|}{$\begin{array}{l}\text { Demographic and clinical } \\
\text { characteristic }\end{array}$} & $\begin{array}{l}\text { Class } 1 \\
\mathrm{n}=217 \\
\end{array}$ & $\begin{array}{l}\text { Class } 2 \\
\mathrm{n}=322 \\
\mathrm{n}(\%) \\
\end{array}$ & $\begin{array}{l}\text { Class } 3 \\
n=80 \\
n(\%)\end{array}$ & $\chi^{2}$ & P value & Cramer's V \\
\hline \multirow{3}{*}{ Gender* } & Man/hov & $100(161)+$ & + & $11(120)+$ & & Pחn1 & ?ח? \\
\hline & Woman/girl & $115(53.0) \dagger$ & $213(66.1) \dagger$ & $60(75.0) \dagger$ & 21.900 & $<0.001$ & 0.22 \\
\hline & $\begin{array}{l}\text { Transgender/ } \\
\text { gender diverse }\end{array}$ & $2(0.9)$ & $18(5.6)$ & $9(11.3)$ & & & \\
\hline \multirow{2}{*}{$\begin{array}{l}\text { Ethnic origin/ } \\
\text { background }\end{array}$} & Caucasian & $137(63.4)$ & $186(57.9)$ & 55 (69.6) & 4.242 & 0.120 & 0.08 \\
\hline & $\begin{array}{l}\text { Another } \\
\text { background }\end{array}$ & 79 (36.6) & $135(42.1)$ & $24(30.4)$ & & & \\
\hline Born in Canada & & $188(87.0)$ & $283(87.9)$ & 71 (88.8) & 0.180 & 0.914 & 0.02 \\
\hline $\begin{array}{l}\text { First language } \\
\text { English }\end{array}$ & & $196(90.7)$ & $292(90.7)$ & 74 (92.5) & 0.272 & 0.873 & 0.02 \\
\hline Student & & $128(59.3)$ & $216(67.1)$ & $50(62.5)$ & 3.485 & 0.175 & 0.08 \\
\hline \multirow{2}{*}{$\begin{array}{l}\text { Employment } \\
\text { status }\end{array}$} & Employed & $135(66.5)$ & $190(64.0)$ & $49(67.1)$ & 0.467 & 0.792 & 0.03 \\
\hline & Unemployed & $68(33.5)$ & $107(36.0)$ & $24(32.9)$ & & & \\
\hline \multirow[t]{2}{*}{$\begin{array}{l}\text { Region of } \\
\text { residence }\end{array}$} & $\begin{array}{l}\text { Large city or } \\
\text { suburbs }\end{array}$ & $133(61.3) \dagger$ & $218(67.7)$ & $63(78.8) \dagger$ & 8.248 & 0.016 & 0.12 \\
\hline & $\begin{array}{l}\text { Small city, town, } \\
\text { village, rural }\end{array}$ & $84(38.7) \dagger$ & $104(32.3)$ & $17(21.3) \dagger$ & & & \\
\hline \multirow{3}{*}{$\begin{array}{l}\text { Number of } \\
\text { people living } \\
\text { with }\end{array}$} & $0-1$ & 30 (14.3) & $58(19.0)$ & $14(17.9)$ & 2.066 & 0.724 & 0.04 \\
\hline & $2-4$ & 151 (71.9) & $205(67.0)$ & $53(67.9)$ & & & \\
\hline & $5+$ & 29 (13.8) & $43(14.1)$ & $11(14.1)$ & & & \\
\hline \multirow[t]{2}{*}{ Living situation } & $\begin{array}{l}\text { With parents/ } \\
\text { grandparents }\end{array}$ & $167(77.0)$ & $240(74.5)$ & $54(67.5)$ & 2.752 & 0.253 & 0.07 \\
\hline & Other & $50(23.0)$ & $82(25.5)$ & $26(32.5)$ & & & \\
\hline \multirow{2}{*}{$\begin{array}{l}\text { Self-rated } \\
\text { physical health }\end{array}$} & Good to excellent & 186 & $259(80.7)$ & $61(76.3)$ & 5.156 & 0.076 & 0.09 \\
\hline & Fair or poor & $29(13.5)$ & $62(19.3)$ & 19 (23.8) & & & \\
\hline \multirow[t]{3}{*}{ GAIN-SS } & $\begin{array}{l}\text { Internalising } \\
\text { disorder }\end{array}$ & $79(37.6) \dagger$ & $184(57.5) \dagger$ & $57(77.0) \dagger$ & 39.693 & $<0.001$ & 0.26 \\
\hline & $\begin{array}{l}\text { Externalising } \\
\text { disorder }\end{array}$ & $47(22.4) \dagger$ & 85 (26.6) & $34(45.9) \dagger$ & 15.536 & $<0.001$ & 0.16 \\
\hline & $\begin{array}{l}\text { Substance use } \\
\text { disorder }\end{array}$ & 21 (10.0) & $42(13.1)$ & $9(12.2)$ & 1.226 & 0.542 & 0.05 \\
\hline \multirow{4}{*}{$\begin{array}{l}\text { Mood } \\
\text { states class } \\
\text { membership }\end{array}$} & Class 1 & $112(51.6) \dagger$ & $151(46.9)$ & $7(8.8) \dagger$ & 216.631 & $<0.001$ & 0.42 \\
\hline & Class 2 & 68 (31.3)† & $14(4.3) \dagger$ & $0(0.0) \dagger$ & & & \\
\hline & Class 3 & $32(14.7) \dagger$ & 117 (36.3)† & $38(47.5) \dagger$ & & & \\
\hline & Class 4 & $5(2.3) \dagger$ & $40(12.4)$ & $35(43.8) \dagger$ & & & \\
\hline \multirow{3}{*}{$\begin{array}{l}\text { Substance } \\
\text { use class } \\
\text { membership }\end{array}$} & Class 1 & $131(60.4)$ & $194(60.2)$ & 39 (48.8) & 4.193 & 0.380 & 0.06 \\
\hline & Class 2 & $58(26.7)$ & $87(27.0)$ & $26(32.5)$ & & & \\
\hline & Class 3 & 28 (12.9) & $41(12.7)$ & 15 (18.8) & & & \\
\hline
\end{tabular}

*Significance test conducted on man/boy versus woman/girl due to sample size; when including transgender/gender diverse participants in the significance test, these youth were significantly less likely to be in class 1 and significantly more likely to be in class 3.

†Post hoc test $\mathrm{p}<0.05$. 
using remote means; this is an important area for future research. Other contextual factors include the move into the darker winter months, ${ }^{53}$ interruptions in new seasonal activities and the prolonged move to a less active lifestyle associated with COVID-19 restrictions, ${ }^{34}$ all of which may also impact mental health. It is therefore essential that we understand how youth mental health is affected through a prospective lens, in the medium and long terms, in order to respond rapidly and effectively to emerging needs.

Youth are a heterogeneous group, with different experiences and needs. This holds true during the pandemic. Girls and young women typically demonstrate higher rates of mood symptoms, ${ }^{54}$ which remains true during the COVID-19 pandemic, in terms of both mood symptoms and COVID-19 worries. Youth with transgender/ gender diverse identities are a vulnerable group in terms of mental health and COVID-19. ${ }^{31}$ Youth with physical health challenges also appear to be more affected in their mental health during COVID-19 than those without physical health concerns, ${ }^{26}$ and their particular need for integrated care should be taken into consideration. ${ }^{55}$

In addition, the current finding that youth living in urban or suburban settings, where COVID-19 infection rates are higher, are experiencing heightened mental health challenges and COVID-19 worries merits attention. A study conducted among adult outpatients in China during COVID-19 demonstrated heightened mental health concerns in those living in urban areas as opposed to rural, interpreted to reflect in part the more dense living situations, more extensive media coverage and more impact on employment. ${ }^{56}$ These concerns may also be experienced among young people in Canada. However, those findings stand in contrast to suggestions that those living in rural areas will experience more impacts due to a lack of internet connection and the digital divide.$^{57}$ A study also found higher mental health concerns among people living in larger households, ${ }^{56}$ reflected again in the current study. This is a concern of note for youth mental health, given that youth living with others may experience more challenges with confidentiality when seeking virtual services. ${ }^{30} 58$ Attending to confidentiality concerns and technological barriers is important in improving the utilisation of virtually delivered mental health and substance use services.

Public health and mental health and substance use service research, evaluations and system-level responses must take heterogeneity in the population into account and provide diverse options to reach different youth. To do so, a key component is to engage with diverse youth locally to hear from youth themselves about what they need and want to cocreate research evaluating and solutions supporting mental health, substance use and wellbeing during the pandemic and beyond. ${ }^{59}$ By engaging young people in cocreating the research and evaluation approaches and the solutions to emerging projects, initiatives can become more attuned to the needs of youth and more effective at addressing these needs. ${ }^{456061}$

\section{Strengths and limitations}

This study prospectively and longitudinally examined mental health and substance use at a bimonthly intervals beginning early in the pandemic. It used a measurement tool designed to understand the impacts of the COVID-19 pandemic on youth. ${ }^{46}$ However, some limitations are to be noted. Mental health and substance use ratings for before the pandemic were reported retrospectively and may have been subject to recall bias. Recruitment bias is also possible, as the severity of mental health and substance use challenges may have differentially affected study participation. The sample was not representative and some diverse groups of youth may not have been reached, particularly those without internet access; the results may therefore not be generalisable to Canadian youth as a whole. It is unknown the degree to which mental health status during the pandemic will have longterm impacts leading to a mental illness trajectory or treatment requirements; future outcomes research will be required. Multiyear longitudinal monitoring is required to examine long-term impacts as stressors related to disruptions in developmental milestones and broader impacts accumulate for vulnerable youth, ${ }^{35}$ including modelling over the medium term with additional waves of the virus and vaccine availability, as restrictions are increased or reduced and as enhanced treatment options become available.

\section{CONCLUSIONS}

Youth mental health has been affected by the COVID-19 pandemic, and youth have substantial concerns related to the pandemic. Symptom levels and concerns are evolving over time, in line with COVID-19 infection rates and potentially evolving with seasonal factors affecting young people. In order to address youth mental health concerns during this public health emergency, it is essential that we continue to monitor the evolving impacts of the pandemic on mental health. It is also essential that we engage directly with youth to cocreate pandemic response strategies and mental health service adaptations to best meet the needs of young people.

Acknowledgements We would like to thank the members of the Youth Engagement Initiative at the Centre for Addiction and Mental Health for their insights into the findings. We would also like to thank the youth participants in the study.

Contributors LDH contributed to designing the research, oversaw the conduct of the study, analysed and interpreted the data and drafted the manuscript. PS, KC, $\mathrm{DC}, \mathrm{AC}$ and ANV contributed to designing the research, interpreted the data and reviewed the manuscript. JH contributed to designing the research, oversaw the conduct of the study, interpreted the data, reviewed the manuscript and provided study leadership; JH is the overall guarantor of the work.

Funding This study was financially supported by the Canadian Institutes of Health Research and the Margaret and Wallace McCain Centre for Child, Youth and Family Mental Health.

Disclaimer The funders had no role in the research.

Competing interests None declared.

Patient consent for publication Consent obtained directly from patient(s) 
Ethics approval This study was approved by the Research Ethics Board of the Centre for Addiction and Mental Health (046-2020).

Provenance and peer review Not commissioned; externally peer reviewed.

Data availability statement Data are available upon reasonable request. Data are available upon Research Ethics Board approval.

Supplemental material This content has been supplied by the author(s). It has not been vetted by BMJ Publishing Group Limited (BMJ) and may not have been peer-reviewed. Any opinions or recommendations discussed are solely those of the author(s) and are not endorsed by BMJ. BMJ disclaims all liability and responsibility arising from any reliance placed on the content. Where the content includes any translated material, BMJ does not warrant the accuracy and reliability of the translations (including but not limited to local regulations, clinical guidelines, terminology, drug names and drug dosages), and is not responsible for any error and/or omissions arising from translation and adaptation or otherwise.

Open access This is an open access article distributed in accordance with the Creative Commons Attribution Non Commercial (CC BY-NC 4.0) license, which permits others to distribute, remix, adapt, build upon this work non-commercially, and license their derivative works on different terms, provided the original work is properly cited, appropriate credit is given, any changes made indicated, and the use is non-commercial. See: http://creativecommons.org/licenses/by-nc/4.0/.

\section{ORCID iDs}

Lisa D Hawke http://orcid.org/0000-0003-1108-9453

Kristin Cleverley http://orcid.org/0000-0002-2822-2129

Joanna Henderson http://orcid.org/0000-0002-9387-5193

\section{REFERENCES}

1 World Health Organization. WHO Timeline - COVID-19 2020. Available: https://www.who.int/news/item/29-06-2020-covidtimeline [Accessed 15 Oct 2020].

2 Public Health Agency of Canada. Community-based measures to mitigate the spread of coronavirus disease (COVID-19) in Canada: government of Canada, 2020. Available: https://www.canada.ca/en/ public-health/services/diseases/2019-novel-coronavirus-infection/ health-professionals/public-health-measures-mitigate-covid-19. html\#_Physical_distancing

3 Duan L, Zhu G. Psychological interventions for people affected by the COVID-19 epidemic. Lancet Psychiatry 2020;7:300-2.

4 Yao H, Chen J-H, Xu Y-F. Patients with mental health disorders in the COVID-19 epidemic. Lancet Psychiatry 2020;7:e21.

5 Ho CS, Chee CY, Ho RC. Mental health strategies to combat the psychological impact of coronavirus disease 2019 (COVID-19) beyond paranoia and panic. Ann Acad Med Singap 2020;49:1-3.

6 Holmes EA, O'Connor RC, Perry VH, et al. Multidisciplinary research priorities for the COVID-19 pandemic: a call for action for mental health science. Lancet Psychiatry 2020;7:547-60.

7 Courtney D, Watson P, Battaglia M, et al. COVID-19 impacts on child and youth anxiety and depression: challenges and opportunities. Can J Psychiatry 2020;65:688-91.

8 Brooks SK, Webster RK, Smith LE, et al. The psychological impact of quarantine and how to reduce it: rapid review of the evidence. Lancet 2020;395:912-20.

9 Wang QQ, Kaelber DC, Xu R. COVID-19 risk and outcomes in patients with substance use disorders: analyses from electronic health records in the United States. Mol Psychiatry 2020.

10 Singh S, Roy D, Sinha K, et al. Impact of COVID-19 and lockdown on mental health of children and adolescents: a narrative review with recommendations. Psychiatry Res 2020;293:113429.

11 Xiong J, Lipsitz O, Nasri F, et al. Impact of COVID-19 pandemic on mental health in the general population: a systematic review. J Affect Disord 2020;277:55-64.

12 Santabárbara J, Lasheras I, Lipnicki DM, et al. Prevalence of anxiety in the COVID-19 pandemic: an updated meta-analysis of communitybased studies. Prog Neuropsychopharmacol Biol Psychiatry 2021;109:110207.

13 Bueno-Notivol J, Gracia-García P, Olaya B, et al. Prevalence of depression during the COVID-19 outbreak: a meta-analysis of community-based studies. Int J Clin Health Psychol 2021;21:100196.

14 Perrin PC, McCabe OL, Everly GS, et al. Preparing for an influenza pandemic: mental health considerations. Prehosp Disaster Med 2009;24:223-30.

15 Boyle $\mathrm{MH}$, Georgiades K. Disorders of childhood and adolescence. In: Cairney J, Streiner D, eds. Mental disorders in Canada: an epidemiological perspective. Toronto, Ontario: University of Toronto Press, 2009.

16 Belfer ML. Child and adolescent mental disorders: the magnitude of the problem across the globe. J Child Psychol Psychiatry 2008;49:226-36

17 Baxter AJ, Scott KM, Vos T, et al. Global prevalence of anxiety disorders: a systematic review and meta-regression. Psychol Med 2013;43:897-910.

18 Auerbach RP, Mortier P, Bruffaerts R, et al. Who world mental health surveys international college student project: prevalence and distribution of mental disorders. J Abnorm Psychol 2018;127:623-38.

19 Boak A, Elton-Marshall T, Mann RE. Drug use among Ontario students, 1977-2019: detailed findings from the Ontario student drug use and health survey (OSDUHS). Toronto, ON: Centre for Addiction and Mental Health, 2020.

20 Kessler RC, Angermeyer M, Anthony JC, et al. Lifetime prevalence and age-of-onset distributions of mental disorders in the world Health organization's world mental health survey initiative. World Psychiatry 2007;6:168-76.

21 Kessler RC, Amminger GP, Aguilar-Gaxiola S. Age of onset of mental disorders: a review of recent literature. Curr Opin Psychiatry 2007;20:359-64.

22 Arnett JJ. Emerging adulthood: the winding road from the late teens through the twenties. New York, NY, US: Oxford University Press, 2004.

23 d'Entremont L, Gregor M, Kirou E, et al. Developmental milestones for productivity occupations in children and youth: An integrative review. Work 2017;56:75-89.

24 Hawke LD, Barbic SP, Voineskos A. Impacts of COVID-19 on youth mental health, substance use, and well-being: a rapid survey of clinical and community samples. Canadian J Psych 2020;65:701-9. doi:10.1111/eip.13052

25 Hamza CA, Ewing L, Heath NL. When social isolation is nothing new: a longitudinal study psychological distress during COVID-19 among university students with and without preexisting mental health concerns. Educational Publishing Foundation, 2020.

26 Hawke LD, Monga S, Korczak D, et al. Impacts of the COVID-19 pandemic on youth mental health among youth with physical health challenges. Early Interv Psychiatry 2021;15:1146-53. doi:10.1111/ eip. 13052

27 Liang L, Ren H, Cao R, et al. The effect of COVID-19 on youth mental health. Psychiatr Q 2020;91:841-52.

28 Shanahan L, Steinhoff A, Bechtiger L, et al. Emotional distress in young adults during the COVID-19 pandemic: evidence of risk and resilience from a longitudinal cohort study. Psychol Med 2020;150:1-10.

29 Son C, Hegde S, Smith A, et al. Effects of COVID-19 on college students' mental health in the United States: interview survey study. J Med Internet Res 2020;22:e21279.

30 Fish JN, McInroy LB, Paceley MS, et al. "I'm kinda stuck at home with unsupportive parents right now": LGBTQ youths' experiences with COVID-19 and the importance of online support. J Adolesc Health 2020;67:450-2.

31 Hawke LD, Hayes E, Darnay K, et al. Mental health among transgender and gender diverse youth: an exploration of effects during the COVID-19 pandemic. Psychol Sex Orientat Gend Divers 2021;8:180-7.

32 Liu CH, Zhang E, Wong GTF, et al. Factors associated with depression, anxiety, and PTSD symptomatology during the COVID-19 pandemic: clinical implications for U.S. young adult mental health. Psychiatry Res 2020;290:113172.

33 Moore SA, Faulkner G, Rhodes RE, et al. Impact of the COVID-19 virus outbreak on movement and play behaviours of Canadian children and youth: a national survey. Int J Behav Nutr Phys Act 2020;17:85

34 Zheng C, Huang WY, Sheridan S, et al. COVID-19 pandemic brings a sedentary lifestyle in young adults: a cross-sectional and longitudinal study. Int J Environ Res Public Health 2020;17:6035.

35 Wade M, Prime H, Browne DT. Why we need longitudinal mental health research with children and youth during (and after) the COVID-19 pandemic. Psychiatry Res 2020;290:113143-43.

36 Racine N, Cooke JE, Eirich R, et al. Child and adolescent mental illness during COVID-19: a rapid review. Psychiatry Res 2020;292:113307-07.

37 Statistics Canada. A portrait of Canadian youth: March 2019 updates 2019. Available: https://www150.statcan.gc.ca/n1/pub/11-631-x/11631-x2019003-eng.htm [Accessed 15 May 2020].

38 Henderson JL, Cheung A, Cleverley K, et al. Integrated collaborative care teams to enhance service delivery to youth with mental health and substance use challenges: protocol for a pragmatic randomised controlled trial. BMJ Open 2017;7:e014080. 
39 Henderson JL, Brownlie EB, McMain S, et al. Enhancing prevention and intervention for youth concurrent mental health and substance use disorders: the research and action for teens study. Early Interv Psychiatry 2019:13:110-9.

40 Hawke LD, Koyama E, Henderson J. Cannabis use, other substance use, and co-occurring mental health concerns among youth presenting for substance use treatment services: sex and age differences. J Subst Abuse Treat 2018;91:12-19.

41 Government of Ontario. Ontario enacts declaration of emergency to protect the public. Queen's Printer for Ontario, 2020. Available: https://news.ontario.ca/opo/en/2020/03/ontario-enactsdeclaration-of-emergency-to-protect-the-public.html [Accessed 1 Jun 2020].

42 Public Health Ontario. COVID-19 in Ontario: focus on October 25, 2020 to October 31, 2020. Weekly epidemiological summary. Toronto, Ontario, Canada, 2020.

43 Harris PA, Taylor R, Thielke R, et al. Research electronic data capture (REDCap) - A metadata-driven methodology and workflow process for providing translational research informatics support. J Biomed Inform 2009;42:377-81.

44 Heffernan OS, Herzog TM, Schiralli JE, et al. Implementation of a youth-adult partnership model in youth mental health systems research: challenges and successes. Health Expect 2017;20:1183-8.

45 Hawke LD, Relihan J, Miller J, et al. Engaging youth in research planning, design and execution: practical recommendations for researchers. Health Expect 2018;21:944-9.

46 Merikangas K, Milham M, Stringaris A. The coronavirus health impact survey (CRISIS). Bethesda, MD: Intramural Research Program, National Institute of Mental Health and the Child Mind Institute, 2020. https://github.com/nimh-mbdu/CRISIS

47 Nikolaidis A, Paksarian D, Alexander L, et al. The coronavirus health and impact survey (crisis) reveals reproducible correlates of pandemic-related mood states across the Atlantic. medRxiv 2020

48 Dennis ML, Chan Y-F, Funk RR. Development and validation of the GAIN short screener (GSS) for internalizing, externalizing and substance use disorders and crime/violence problems among adolescents and adults. Am J Addict 2006;15:80-91.

49 Dennis ML, Feeney T, Hanes Stevens LV. Global Appraisal of Individual Needs-Short Screener (GAIN-SS):Administration and
Scoring Manual Version 2.0.3. Bloomington, IL: Chestnut Health Systems, 2008.

50 Nylund-Gibson K, Choi AY. Ten frequently asked questions about latent class analysis. Trans/ Issues Psychol Sci 2018;4:440-61.

51 Dziak JJ, Lanza ST, Tan X. Effect size, statistical power and sample size requirements for the bootstrap likelihood ratio test in latent class analysis. Struct Equ Modeling 2014;21:534-52.

52 Hansen B, Lang M. Back to school blues: seasonality of youth suicide and the academic calendar. Econ Educ Rev 2011;30:850-61.

53 Magnusson A, Partonen T. The diagnosis, symptomatology, and epidemiology of seasonal affective disorder. CNS Spectr 2005;10:625-34.

54 Wiens K, Bhattarai A, Pedram P, et al. A growing need for youth mental health services in Canada: examining trends in youth mental health from 2011 to 2018. Epidemiol Psychiatr Sci 2020;29:e115-e15.

55 Asarnow JR, Rozenman M, Wiblin J, et al. Integrated medicalbehavioral care compared with usual primary care for child and adolescent behavioral health. JAMA Pediatr 2015;169:929-37.

56 Liu L, Xue P, Li SX, et al. Urban-Rural disparities in mental health problems related to COVID-19 in China. Gen Hosp Psychiatry 2021;69:119-20.

57 Summers-Gabr NM. Rural-urban mental health disparities in the United States during COVID-19. Psychological Trauma: Theory, Research, Practice, and Policy 2020;12:S222-4.

58 Hawke LD, Sheikhan NY, MacCon K, et al. Going virtual: youth attitudes toward and experiences of virtual mental health and substance use services during the COVID-19 pandemic. BMC Health Services Research 2021;21:1-10.

59 Centre for Children and Young People's Participation. COVID-19: Children's Participation in shaping responses. 21. University of Central Lancashire, 2020.

60 Hawke LD, Mehra K, Settipani C, et al. What makes mental health and substance use services youth friendly? A scoping review of literature. BMC Health Serv Res 2019;19:257.

61 Brownlie EB, Chaim G, Heffernan O, et al. Youth services system review: moving from knowledge gathering to implementation through collaboration, youth engagement, and exploring local community needs. Can J Commun Ment Health 2017;36:133-49. 